\title{
O cotidiano de profissionais da saúde nos cuidados paliativos: um estudo na fenomenologia social de Alfred Schültz
}

\section{The daily life of health professionals in palliative care: a study in social phenomenology by Alfred Schültz}

\author{
Beatriz Rezende Marinho da Silveira' $\bullet$ Diego Dias de Araújo $^{2} \bullet$ Daniel Vinicius Alves Silva ${ }^{3}$ \\ Maria Aparecida Vieira ${ }^{4}$ Cristina Andrade Sampaio ${ }^{5}$
}

\begin{abstract}
RESUMO
Objetivo: Investigar a compreensão e significados atribuídos às experiências que ocorrem no cotidiano de profissionais da saúde em uma Associação de Apoio a pessoas com câncer em cuidados paliativos. Métodos:Trata-se de pesquisa qualitativa, com abordagem da Fenomenologia Social de Alfred Schütz, que propõe analisar as realidades construídas pelas pessoas e para si próprias, a partir de suas experiências intersubjetivas. Participaram quatro profissionais da saúde que desenvolvem ações de cuidados paliativos no cenário deste estudo.A investigação se deu, inicialmente, pela realização de duas reuniões de aproximação das pesquisadoras com o campo de estudo, ocorridas no período de julho a outubro de 2018 . $O$ instrumento utilizado para a coleta das informações foi a entrevista fenomenológica. Resultados:A preparação dos profissionais para trabalhar em cuidados paliativos, apresenta caminhos diversos no que se refere a experiências profissionais; pessoais; formação acadêmica; iniciativas particulares e vivências com o câncer na própria família. A experiência no trabalho e no cuidar de pessoas com câncer e acolher seus familiares em uma Associação de Apoio revelou vivências de solidariedade; o compartilhamento de responsabilidades; a necessidade de comunicação e o preparo espiritual dos profissionais como diferenciais para o sucesso do tratamento. Conclusão:A partir da compreensão do processo que permeia o trabalho em cuidados paliativos emergiram nos discursos subjetivos dos cuidadores a pessoa com câncer a 'relação com o outro' e revelaram desafios diários de convivência; conflitos; reflexões pessoais e de atitude diante do enfrentamento do câncer.As ações sinalizampara a integralidade e a resolubilidade dos cuidados, que requerem um olhar especial para o ser humano.

Palavras-chave: Neoplasias; Cuidados Paliativos; Emoções.
\end{abstract}

\begin{abstract}
Objective:To investigate the understanding and meanings attributed to the experiences that occur in the daily life of health professionals in a Support Association for people with cancer in palliative care. Methods: This is a qualitative research approached by Alfred Schütz's Social Phenomenology, which proposes to analyze the realities constructed by people and for themselves, based on their intersubjective experiences. Four health professionals who develop palliative care actions in the scenario of this study participated. Initially, the investigation was carried out through two meetings of researchers approaching the field of study, held from July to October 2018. The instrument used to collect the information was the phenomenological interview. Results:The preparation of professionals to work in palliative care presents different paths with regard to professional experiences; personal; academic training; particular initiatives and experiences with cancer in their own family. The experience in working and caring for people with cancer and welcoming their families in a SupportAssociation revealed experiences of solidarity; the sharing of responsibilities; the need for communication and the spiritual preparation of professionals as differentials for the success of treatment. Conclusion: From the understanding of the process that permeates the work in palliative care emerged in the subjective discourses of caregivers the person with cancer the 'relationship with the other' and revealed daily challenges of coexistence; conflicts; personal and attitude reflections on coping with cancer.The actions signal the completeness and the solvability of care, which require a special look at the human being.
\end{abstract}

Key-words: Neoplasms; Palliative Care; Emotions.

NOTA

I. Mestre em Saúde Pública pela Faculdade de Medicina daUniversidade Federal de Minas Gerais (UFMG). Doutoranda do Programa de Pós-Graduação em Ciências da Saúde da Universidade Estadual de Montes Claros (UNIMONTES). Professora do Departamento de Enfermagem daUNIMONTES.

2. Doutor em Enfermagem pela Escola de Enfermagem da Universidade Federal de Minas Gerais (UFMG). Professor do Departamento de Enfermagem da Universidade Estadual de Montes Claros (UNIMONTES).

3. Enfermeiro Assistêncial do Hospital Irmandade Nossa Senhora das Mêrces - Santa Casa de Montes Claros/Minas Gerais.

4. Doutora em Ciências pela Universidade Federal de São Paulo (UNIFESP). Professora Aposentada do Departamento de Enfermagem da Universidade Estadual de Montes Claros (UNIMONTES).Professora do Mestrado Profissional em Cuidado Primário em Saúde da UNIMONTES.

5. Doutora em Saúde Coletiva pela Universidade Federal de São Paulo (UNIFESP).Professora do Departamento de Saúde Mental e Saúde Coletiva da Universidade Estadual de Montes Claros (UNIMONTES) e do Programa de Pós-graduação em Ciências da Saúde da Universidade Estadual de Montes Claros (UNIMONTES). 


\section{INTRODUÇÃO}

As transições demográficas, ocorridas mais intensamente na segunda metade do século passado, determinaram o aumento da longevidade do ser humano e uma tendência crescente das doenças crônicas degenerativas, constituindo desafios para a saúde pública'.

Entre as doenças crônicas degenerativas, o câncer destaca-se por se constituir na segunda causa de morte no Brasil. Estimativas apresentadas pelo Instituto $\mathrm{Na}$ cional do Câncer sobre a incidência do câncer no biênio 2018-2019 apontam o surgimento aproximado de 582.590 mil casos $^{2}$.

Os cuidados voltados para as pessoas com câncer requerem ações e serviços embasados no cuidado integral que contempla a prevenção, a detecção precoce, o diagnóstico, o tratamento e os cuidados paliativos ${ }^{3}$.

Segundo a Organização Mundial da Saúde (OMS), 20 milhões de pessoas irão necessitar de cuidados paliativos no mundo, determinando um novo perfil epidemiológico e a emergência de discussões sobre o processo de morrer com qualidade de vida e dignidade ${ }^{4}$.

O processo da terminalidade é um dos momentos mais significativos para os indivíduos, familiares e seus cuidadores, representando uma sobrecarga emocional com repercussões físicas, psicossociais e espirituais ${ }^{5}$.

O desdobramento do adoecimento revela uma interação entre saúde e subjetividade, que se caracteriza por uma síntese da experiência humana na sua articulação com o social ${ }^{6}$.

A relação social é o elemento fundamental na interpretação dos significados da ação dos sujeitos no mundo cotidiano, constituindo os fios condutores que viabilizam a construção social dos sujeitos e influência as suas relações ${ }^{7}$. A fenomenologia social de Alfred Schütz compreende que toda ação humana estabelecida no mundo social se contextualiza na intersubjetividade dos sujeitos, a partir da relação social que se estabelece no mundo da vida ${ }^{8-9}$.

Assim, a ação social do cuidar considera ações e reações de outros indivíduos, em que se deve orientar o alívio do sofrimento, focalizada na pessoa e não na doença, e isso valoriza trocas intersubjetivas entre quem cuida e quem é cuidado ${ }^{10}$.

Para compreender como se dá essa relação, cuidador e pessoa cuidada, torna-se importante considerar a formação profissional e a educação permanente em saúde, por meio de práticas que visem à aquisição de saberes, competências e atitudes dos profissionais de saúde, com possíveis impactos na qualidade de vida, da assistência implementados aos pacientes em cuidados paliativos.

Nesse contexto, emergiu a seguinte questão:Qual a compreensão e significados atribuídos por profissionais da saúde na assistência a pacientes em cuidados paliati- vos? Na perspectiva da fenomenologia social de Alfred Schütz, este estudo se propôs a investigar a compreensão e significados atribuídos às experiências que ocorrem no cotidiano de profissionais da saúde em uma Associação de Apoio a pessoas com câncer.

\section{MÉTODO}

Trata-se de estudo qualitativo na perspectiva da Fenomenologia Social de Alfred Schütz. A Fenomenologia Social de Alfred Schütz é pautada na pessoa que vivencia a experiência de determinado fenômeno e considera que somente o ator envolvido pode aludir o que anseia com a ação. Esse referencial revelou-se condizente com o fenômeno da assistência em cuidados paliativos, por envolver as experiências sociais vividas em comunidade e entre indivíduos. Comportamentos espontâneos experienciados pelos sujeitos ao estabelecerem relações direcionadas por meio de uma ação intencional caracterizam-se na ação social, que envolve inúmeros sentimentos vivenciados no mundo da vida, no qual desempenham suas ações e compartilham seus sentimentos ${ }^{7-9}$.

Os profissionais de saúde, sujeitos deste estudo, ao realizarem a prática dos cuidados paliativos, incluem ações e interações com o indivíduo, seja na assistência à incapacidade ocasionada pela doença, até o apoio psicológico aos familiares. As trocas intersubjetivas de quem cuida e de quem é cuidado favorecem o alívio do sofrimento ancorado na pessoa e não em seu adoecimento ${ }^{10}$.

O setting deste estudo foi a Associação Presente de Apoio a Pacientes com Câncer localizada no Estado de Minas Gerais, Brasil.Trata-se de uma instituição sem fins lucrativos, fundada em 2004, e tem como missão promover assistência, cuidado e amparo a jovens, adultos e idosos carentes com câncer e atuar na prevenção e diagnóstico precoce da doença. Seus serviços abrangem o município de Montes Claros e a região do norte do Estado de Minas Gerais. Os dados foram coletados no período de julho a outubro de 2018.

A escolha dos participantes se deu por conveniência. Foram convidadas e incluídas nesta pesquisa quatro profissionais de saúde, que realizavam cuidados paliativos na Associação Presente de Assistência a Pacientes com Câncer, com nível superior, por se acreditar que tiveram uma formação profissional que proporcionou maior aproximação e capacitação para atuar com cuidados paliativos.Essa escolha foi ao encontro da Fenomenologia de Alfred Schutz e Martin Heidegger, que estão entre os fenomenólogos que mais têm alicerçado o interesse no esclarecimento de fenômenos que atingem o universo feminino".

A investigação do estudo se deu, inicialmente, pela realização de duas reuniões de aproximação das pesquisadoras com o campo de estudo. A primeira, a fim de 
apresentar a pesquisa às profissionais e a segunda para aproximá-las dos preceitos éticos necessários para a efetiva participação na pesquisa e convidá-las a participar do estudo. Ainda nessa reunião, as participantes assinaram o Termo de Consentimento Livre e Esclarecido (TCLE). Esses encontros ocorreram em adequadas dependências da Associação.

O instrumento utilizado para a coleta das informações foi uma entrevista semiestruturada, oferecendo às pesquisadoras liberdade para introduzir-se na consciência do fenômeno a ser descrito. Optou-se pela entrevista fenomenológica ao considerar que essa modalida de procura perceber o sentido do comportamento, efetuando a leitura da verdade, que culmina em ter uma visão de unidade e totalidade, visão de ultrapassagem do pensamento objetivo situando o comportamento para além de conteúdos particulares motores e visuais, é mostrar sua totalidade e não seus fragmentos ${ }^{12}$.

Para que as participantes pudessem expressar o significado de suas ações desenvolvidas no mundo de suas relações de trabalho, elaborou-se um roteiro para as entrevistas, que continha as seguintes questões norteadoras: Qual(ais) o(s) motivos que a levaram a trabalhar com cuidados paliativos na Associação Presente? Como foi sua preparação para o entendimento e manejo de cuidados paliativos dos pacientes oncológicos e sua família? Como é seu cotidiano na prestação de cuidados paliativos na Associação Presente? Quais as perspectivas futuras, pessoal e profissional, nesta etapa de sua vida frente aos cuidados paliativos?

Após o aceite, ocorrido na segunda reunião, estabeleceu-se, em comum acordo com as participantes, que o roteiro com as questões norteadoras seriam refletidas e respondidas pelas entrevistadas na ocasião em que optassem por respondê-las. Assim, foi entregue a cada participante um gravador e estabelecida uma data adequada para recebê-lo. As pesquisadoras colocaram-se à disposição para futuros esclarecimentos.

Em data pré-agendada, encerrou-se a coleta de dados e foram realizadas as transcrições na íntegra das falas, com vocabulário próprio dos sujeitos/atore desta pesquisa, após a audição repetida das gravações.

Para a análise das informações, foram utilizados os passos referidos e sugeridos por pesquisadores da Fenomenologia Social buscando, por meio das leituras das informações, identificar as unidades de significados, a relação das categorias entre si, chegando, assim, à construção das categorias concretas acerca das experiências vividas e significados revelados por profissionais de saúde que trabalham com cuidados paliativos em uma Associação de apoio a pessoas com câncer.

Este estudo foi realizado em conformidade com a Resolução $n^{\circ} 466$, de 12 de dezembro de 2012, que dis- corre sobre pesquisa com seres humanos, sendo aprovado conforme o Parecer Consubstanciado $n^{\circ} 2.599 .222$ - CAEE n⿳ 866/37/8.9.0000.5 I46. Para preservar o anonimato das participantes, utilizaram-se como códigos a letra $\mathrm{E}$, de entrevistado, e um número ordinal a ela subsequente $(I, 2,3 \ldots)$, conforme a ordem de realização das entrevistas.

\section{RESULTADOS}

Os achados foram interpretados à luz de concepções teóricas da Fenomenologia Social de Alfred Schütz ${ }^{9}$.A partir da interpretação dos resultados, emergiram cinco categorias concretas do vivido: Trajetória dos Profissionais em Cuidados Paliativos; Cuidados Paliativos: significados e motivações; Experiências e Desafios Vividos pela Equipe; Construção de um Cuidado Singular e Lidar com a Finitude da Vida. Tais reflexões, que não devem ser visualizadas de maneira fragmentária, mas sim integrada e complexa, são tecidas a seguir.

\section{Trajetória dos Profissionais em Cuidados Paliativos}

A preparação dos profissionais para trabalhar em cuidados paliativos, revelada nas narrativas, apresenta caminhos diversos que relatam experiências profissionais; pessoais; formação acadêmica; iniciativas particulares e vivências com o câncer na própria família, como expressa o conjunto de discursos:

Já trabalhei em uma Fundação, que é uma casa de apoio a crianças e adolescentes com câncer (EI).

[...] uma experiência pessoal me trouxe uma reflexão muito grande, hoje a vida nos capacita, além do conhecimento técnico, mas é a experiência do dia a dia que nos leva a outras reflexões que são muito maiores. Em 2012 eu perdi meu esposo, ele descobriu um câncer avançado metastático (E2).

Quando terminei o mestrado em 2010, fui fazer uma pósgraduação e foi uma experiência riquíssima, eu me preparei, estou me preparando ainda (E3).

E pelo fato de a gente já trabalhar com pacientes oncológicos, já nos prepara para trabalhar com cuidados paliativos (E4).

\section{Cuidados Paliativos: significados e motivações}

$\mathrm{Na}$ construção dos significados sobre cuidados paliativos, emergiu, das entrevistas a subjetividade latente das vivências das profissionais enquanto cuidadoras de pessoas com câncer. Para os sujeitos deste estudo, o significado sobre cuidados paliativos se traduz na integralidade da assistência e na visão por inteiro do ser humano, físico e espiritual:

É ver o ser humano na sua integralidade e às vezes a gente tem a sensação de que não fazemos muito, mas é o que ele precisa, às vezes uma mudança de decúbito ou 'você aceita uma água?'”O que você gostaria para hoje?'Você quer 
conversar sobre alguma coisa?' Isso é tudo o que o paciente precisa nesse momento (E2).

[...] Então, você percebe o paciente como um todo, apesar da doença muito avançada, apesar de todo histórico que ele traz, mas ele é um ser humano na integralidade, ele tem sonhos, tem raiva, tem medo. Ele experimenta todas as sensações possíveis (E2).

[...] é assim que a gente tem lidado, com esse olhar inteiro (E3).

[...] um paciente com cuidados paliativos requer uma demanda diferenciada. É no atendimento que ele requer uma integralidade maior, você deve se preocupar com o todo do paciente e não ficar focado só na teoria (E4).

$O$ recorte das narrativas sobre os motivos que levaram os sujeitos a trabalhar com cuidados paliativos, uma assistência de natureza complexa e multidimensional, aflorou sentimentos relacionados à realização pessoal, à solidariedade, à descoberta de um significado existencial e de religiosidade:

[...] o paciente tem seu diagnóstico muito avançado e a gente consegue identificar e promover o conforto.Isso me traz uma realização de perceber o que o outro precisa, o que eu posso ser melhor para aquele paciente (E2).

[...] é possível oferecer a dignidade, quando é possível (E2).

O motivo que me levou a trabalhar com cuidados paliativos na Associação foi perceber que muitos que chegavam para se hospedar na casa, chegavam já bastante debilitados, muitos angustiados sem saber exatamente o que estava acontecendo com eles (E3).

É um sentimento muito gostoso, é algo que me preenche, que me traz um significado profundo para minha existência [...] eu percebo a satisfação dos assistidos, dos pacientes, da família, colaboradores da casa, mas volto a dizer, saio sempre de lá com o coração cheio de significado, com muita gratidão a Deus pela oportunidade de alguma forma, mesmo sendo uma formiguinha, aliviar o sofrimento de um ser humano (E3).

[...] um dos motivos, é que gosto muito de trabalhar na área da Saúde. Sempre me vi exercendo minha profissão prestando cuidados aos assistidos (E4).

\section{Experiências e desafios vividos pela equipe}

A experiência no trabalho e no cuidar de pessoas com câncer e acolher seus familiares em uma Associação de Apoio revelou vivências de solidariedade; o compartiIhamento de responsabilidades; a necessidade de comunicação e o preparo espiritual dos profissionais como diferenciais para o sucesso do tratamento:

[...] o trabalho em equipe nos fortalece muito. A gente tem uma equipe muito bacana, em que existe essa comunicação: fisioterapeuta, psicóloga, assistente social, o capelão, o pastor (E2).

A equipe multiprofissional trabalha em conjunto com troca de informação e o compartilhamento de responsabilidades, ela é o diferencial para o sucesso do paciente (E4).
A abordagem voltada para o ser humano em sua integralidade transforma a prática dos cuidados paliativos em um trabalho necessariamente de equipe, com profissionais da área de saúde e assistentes espirituais, de caráter ecumênico ou da religião praticada pela pessoa em cuidados ${ }^{14}$, como descreve E2.

A doença, do ponto de vista da Medicina, não tem a cura, mas a gente fala de uma cura maior, de uma cura espiritual, de uma cura da alma...(E2).

Lidar diariamente com a pessoa em cuidados paliativos requer, a todo momento, enfrentar desafios diários de convivência; conflitos; reflexões pessoais e de atitude diante do enfrentamento da doença:

[...] peço o Espírito Santo para me iluminar, para que eu possa falar para cada pessoa tudo aquilo que ela necessita ouvir e tudo aquilo que seja transformador para ela, ou na aceitação ou no entendimento ou na ação, na atitude necessária para mudarmos o curso a favor de uma vida, a favor de uma pessoa que enfrenta uma doença tão grave como 0 câncer (E3).

\section{Construção de um cuidado singular}

As vozes das profissionais de saúde, dos cuidados paliativos, interpretando o cotidiano em que vivem por meio de suas experiências e suas ações no mundo social, apresentam a percepção de um cuidado peculiar e diferenciado, no qual se tem um olhar especial para o ser humano em sua essência, com ênfase na dignidade humana:

[...] A gente pode ver o ser humano totalmente diferente nos mostrando um novo olhar do que era o ser humano na sua essência [...] o que traz, quais são os sonhos, como ele viu a vida durante este trajeto (E2).

[...] Cada paciente é único, a equipe age baseada em suas necessidades. A gente consegue identificar e promover o melhor conforto, o conforto vai muito além das palavras, além de tudo (E2).

[...] trabalhar com cuidados paliativos é trabalhar com o resgate da dignidade humana, e o meu manejo, então, nasce respeitando o que o outro dá conta, quais são os anseios, como é que ele lida com o seu sofrimento, com suas limitações, com suas perdas de funções. É oferecer para ele e para sua família um leque de opções, que não é pequeno, em que está incluído o alívio profundo do sofrimento humano, alívio da dor, da dispneia, da fadiga, da caquexia (E3).

\section{O lidar com a finitude da vida}

A assistência diária a pessoas com câncer, e, em especial, em cuidados paliativos, é marcada pela vivência das profissionais com o processo de morrer.A equipe se depara com manifestações variadas de sentimentos e emoções que a fazem refletir sobre a existência humana e as relações estabelecidas nos cuidados. A chegada dos pacientes aos cuidados paliativos é o resultado desgastante e uma 
situação/ou uma etapa na qual se assume a aproximação de morte inevitável, no entanto, repleta de sentidos:

É muito dificil trabalhar com pacientes com câncer.A gente sofre junto, a gente chora junto. Não é fácil você lidar com a morte, ainda mais o paciente saber que ele está num tratamento para cuidados paliativos, já é um tratamento que praticamente já está num fim da vida (EI).

É saber que, até que a morte chegue, nós estamos vivos e precisamos celebrar a vida.A vida urge porque no segundo seguinte a gente pode não estar aqui mais (E3).

Nesse processo de lidar com a morte, dúvidas, angústias e questionamentos permeiam os discursos dos sujeitos deste estudo ao se manifestarem:

[...] a impressão inicial que a gente tem é essa: antes de você se preparar realmente, antes de você estudar o que são cuidados paliativos, você só pensa 'eu estou me preparando para morrer', mas não é.Você está se preparando para ter um certo conforto, quando você vier a morrer, a qualquer instante isso pode acontecer (EI).

Eu acompanho muito essa questão, 'vou contar ou não para o paciente' e a medida do que ele quer saber. Existe muito essa sensação de que ele não sabe o que está acontecendo, ele não sabe que a doença está avançada (E2).

\section{DISCUSSÃO}

O preparo da equipe, que presta cuidados na Associação a pessoas com câncer, se deu à semelhança de relatos de outros estudos em que a formação foi adquirida durante a própria prestação dos serviços ${ }^{13-14}$. Em que pese as iniciativas de oferta de disciplinas em cuidados paliativos nos Cursos de Graduação e Pós-Graduação, no Brasil, ainda há um importante déficit de oferta de ensinamentos nessa área ${ }^{15}$.

Embora não haja uma orientação curricular da inserção de cuidados paliativos na graduação, estudos apontam para a necessidade de oferecer ao estudante um contato com os cuidados paliativos proporcionando-lhe a discussão e o aprimoramento das competências nesse cuidar.

Com o envelhecimento da população e o aumento das doenças crônicas em estágios avançados, é necessário que o processo ensino-aprendizagem incorpore a aproximação da teoria e da prática de cuidados paliativos em uma perspectiva da compreensão do ser humano em sua complexidade, em uma abordagem fenomenológica, com o olhar atento a respeito de si e do outro. $O$ ser humano não é um ser apenas biológico, ele também se constitui de processos sociais e culturais'.

Percebe-se, nos discursos subjetivos dos cuidadores de pessoas com câncer, a relação com o outro. $\bigcirc$ processo de cuidar implica em uma relação especifica entre os sujeitos, que se constrói de forma única e singular, no qual os envolvidos estão conscientes um do outro, gerando desdobramentos individuais, relacionais e sociais.
A visão integral do ato de cuidar guarda coerência com a doutrina do Sistema Único de Saúde, integrando aspectos psicossociais e espirituais, abrangendo as várias dimensões do ser humano ${ }^{16}$.

Os discursos revelaram a compreensão dos cuidados paliativos manifestada por uma assistência integral e humanizada, representando uma visão ampliada, em contraposição a um modelo fragmentado e biologicista. Nas expressões das profissionais, ressalta-se uma valorização das dimensões psicológicas e sociais, significando a possibilidade de apreender as necessidades mais abrangentes dos portadores de câncer, que permite uma discussão e compreensão no campo da subjetividade humana ${ }^{17}$.

O princípio da integralidade da assistência está embasado na Política Nacional de Atenção Oncológica, definida na Portaria $n^{\circ} 874 / G M$, de I6/05/2013, que contempla a prevenção, a detecção precoce, o diagnóstico, o tratamento e os cuidados paliativos (BRASIL, 20I3). Para garantir a integralidade e a resolubilidade dos cuidados paliativos, é necessário ir além dos recursos instrumentais e profissionais, é necessário aliar o significado que se dá no encontro dos sujeitos, usuário e trabalhador, em que as relações são estabelecidas no ato de cuidar ${ }^{18}$.

Diferentes emoções são constitutivas da experiência do cuidado. Os motivos expressos pelas participantes se relacionam com as interpretações e construções pelo sujeito a partir de suas experiências intersubjetivas e cotidianas. O sentido subjetivo é produzido no processo de viver e na experiência de trabalhar em cuidados paliativos, que possibilita a elaboração da reflexão no mundo social e cultural do cuidador ${ }^{19}$.

A produção da saúde é a resultante de um conjunto complexo de fatores, que demanda a participação ativa de todos os sujeitos envolvidos, tendo como marca a dimensão social e subjetiva, incorporada ao pensamento sanitário ${ }^{20}$.

Para a efetivação da produção do cuidado, é necessário competência técnica e relacional destacada pelo trabalho de uma equipe multidisciplinar que pode ajudar na busca de estratégias de enfrentamento a doença ${ }^{21}$.

Os cuidados paliativos no Brasil apresentam-se de forma inovadora e vêm ganhando espaço na última década. Diferenciam-se fundamentalmente da medicina curativa por focar no cuidado integral, por meio da prevenção e do controle de sintomas para todos os pacientes que enfrentam doenças graves e a seus familiares ${ }^{14}$.

A Organização Mundial da Saúde preconiza que o modelo de cuidado paliativo deve iniciar o mais precocemente possível, concomitantemente ao tratamento curativo, a fim de buscar o conforto e a qualidade de vida das pessoas e familiares que enfrentam uma doença ameaçadora da vida ${ }^{22}$.

Estudo que comparou a assistência promovida no modelo tradicional e no modelo dos cuidados paliativos 
precoces mostrou que esse apresentou melhor autoavaliação de qualidade e tempo de vida, demonstrando que o modelo proposto pela OMS é factível e traz impactos para a vida dos doentes ${ }^{23}$.

Os sentidos subjetivos produzidos no ato de cuidar de pessoas com câncer são decorrentes de caminhos simbólicos e emocionais das histórias das pessoas, decorrentes dos processos sociais e culturais.

$\mathrm{Na}$ sociedade e nas narrativas das participantes desta pesquisa, constata-se a prática do cuidado marcada por aspectos da subjetividade social relacionada ao papel feminino e nos discursos de gênero. $A$ associação do cuidado com a figura feminina foi historicamente construída representando papeis de responsabilidade materna, cuidado com os filhos e família, expressando o sentido da singularidade da realidade vivida ${ }^{19}$.

Esse olhar especial para o ser humano, com ênfase no cuidar, está identificado na subjetividade social, configurado em diferentes símbolos que mostram a figura feminina entre as profissões do cuidado'.

Apesar de a morte ser parte do ciclo natural da vida, os profissionais dos cuidados paliativos, convivem com ela, necessitam ser constantemente preparados para essa lida, pois são eles que passam mais tempo ao lado do paciente, acompanhando-o no seu processo de morte ${ }^{24}$.

Nos cuidados paliativos, não se convive apenas com o momento da morte, mas com todo o sofrimento da pessoa com câncer e sua família.A relação entre a equipe de saúde e os sujeitos é marcada pela maneira como cada ator convive com o processo de morrer social e culturalmente elaborado. A convivência com o processo de morrer é única para cada profissional como também é peculiar o processo de morrer para o sujeito doente. $O$ contato com o outro e com a imagem da morte lembra ao profissional sua própria finitude ${ }^{13}$.

O cuidador, além de lidar com as necessidades básicas da pessoa com câncer em cuidados paliativos e a experiência da morte, experimenta também o convívio com o sofrimento e questionamentos pessoais perante os sig- nificados da terminalidade da vida, necessitando também de cuidados.

Assim, um olhar especial deve ser dirigido aos profissionais do cuidado paliativo a fim de identificar e apoiar demandas sociais e psicológicas, uma vez que podem apresentar sobrecargas objetivas e subjetivas que requerem uma atenção especial. ${ }^{25}$

\section{CONCLUSÃO}

A compreensão dos significados atribuídos às experiências e vivências que ocorrem no mundo de profissionais da saúde em uma Associação de Apoio às pessoas com câncer em cuidados paliativos permitiu desvelar as ações desempenhadas e indicar motivos e atitudes nos desafios que estes enfrentam cotidianamente.

A fenomenologia social de Alfred Schütz permitiu conhecer os "motivos por que" e os "motivos para que",expressos e inscritos na intersubjetividade das entrevistadas, possibilitando compreender, a partir deem seus discursos, os desafios diários apreendidos na convivência; conflitos; reflexões pessoais e de atitude diante da finitude humana levando-as a pensar sobre as relações estabelecidas nos cuidados paliativos.

Dessa forma, esta investigação sinaliza para reforçar a integralidade e a resolubilidade dos cuidados paliativos, permitindo ressignificar o encontro dos sujeitos, usuário e trabalhador, quando as relações são estabelecidas no ato de cuidar e requerem um olhar especial para o ser humano.

Como limitação deste estudo, cita-se o fato de ter sido realizado com um grupo específico de profissionais que pertenciam a um único serviço de cuidados paliativos, situado em uma determinada realidade social. É válido ressaltar que a condução de outros estudos com profissionais em contextos diferentes não necessariamente convergirá para resultados similares, no entanto, os achados desta pesquisa poderão enriquecer a compreensão do trabalho de profissionais em cuidados paliativos, além de estimular a realização de novas pesquisas na temática. 


\section{REFERÊNCIAS}

I. Gayoso MV, Avila MAG, Silva TA, Alencar RA. Comfort level of caregivers of cancer patients receiving palliative care. Rev Latino-Am Enferm. [Internet].2018[acesso em 01 jul 2019];26: e3029.Disponível em:http://www.scielo.br/pdf/ rlae/v26/0 I04-I I69-rlae-26-e3029.pdf

2. Instituto Nacional de Câncer José de Alencar Gomes Silva (INCA). Coordenação de Prevenção e Vigilância. Estimativa 20 I8: incidência de câncer no Brasil. Rio de Janeiro:INCA;20I7.

3. Ministério da Saúde (BR). Portaria $n^{\circ} 874$, de 16 de maio de 20I3. Institui a Política Nacional para a Prevenção e Controle do Câncer na Rede de Atenção à Saúde das Pessoas com Doenças Crônicas na âmbito do Sistema Único de Saúde (SUS).Brasília: Ministério da Saúde; 2013.

4. Pineli PP, Krasilcic S, Suzuki FA, Maciel MGS. Cuidado Paliativo e Diretrizes Curriculares: inclusão necessária. Revista Brasileira de Educação Médica. 2016[acesso em 01 jul 2019];40(4):540-46. Disponível em: http://www.scielo.br/ pdf/rbem/v40n4/I98I-527I-rbem-40-4-0540.pdf

5. Karkow MC, Girardon-Perlini NMO, Stamm B, Camponogara S, Terra MG, Viero V. Experience of families facing the revelation of the cancer diagnosis in one of its integrants. REME Rev Min Enferm. [Internet].20I5[acesso em 0I jul 2019];19(3):741-46. Disponível em: http://www.reme.org. br/artigo/detalhes/1036

6. Mori VD, González Rey FL. Reflexões sobre o social e o individual na experiência do câncer. Psicologia \& Sociedade, 23(n.esp.) 99-108, 2011.

7. Schütz A. El problema de la realidad social. Buenos Aires: Amorrortu; 2008.

8. Caldeira S, Parecy SM, Maraschin MS, Ross C, Machineski GG, Ribeiro SA. Life experience of elderly smoker women: the view of Alfred Schültz social phenomenology. REME Rev Min Enferm. [Internet]. 2016[acesso em 0I jul 2019];20:e953. Disponível em: http://www.reme.org.br/artigo/detalhes//086

9. Schütz A. Sobre fenomenologia e relações sociais. Petrópolis:Vozes; 2012.

10. Carvalho GAFL, Menezes RMP, Enders BC, Teixeira GA, Dantas DNA, Oliveira DRC.Meanings attributed to palliative care by health professional in the primary care context. Texto Contexto Enferm.[Internet].2018[acesso em 0I jul 2019]; 27(2):e5740016. Disponível em: http://www.scielo. br/pdf/tce/v27n2/en_0104-0707-tce-27-02-e57400 I6.pdf

I I. Silva RV, Oliveira WF. O método Fenomenológico nas pesquisas em saúde no Brasil: uma análise da produção científica. Trab. Educ. Saúde. [Internet].2018[acesso em 05 jul 2019]; |6(3):|42|-4|.Disponível em: http://www.scielo.br/ pdf/tes/v16n3/I678-1007-tes-16-03-1421.pdf

12. Castro EHB. Fenomenologia e Psicologia: a(s) teoria(s) e práticas de pesquisa. Curitiba:Appris; 2017.

13. Kappaun NRC, Gomez CM. O trabalho de cuidar de pacientes terminais com câncer. Ciência \& Saúde Coletiva. [Internet].20I3[acesso em I0 jul 2019];18(9):2549-57.
Disponível em: https://www.scielosp.org/scielo.php?pi$\mathrm{d}=\mathrm{S}|4|$ | 3-8| 2320 | 300 I 700009\&script=sci_arttext\&tlng=pt

14. Gomes ALZ, Othero MB. Cuidados Paliativos. Estudos Avançados.2016[acesso em 05 jul 2019];30(88): I 55-66.Disponível em: http://www.revistas.usp.br/eav/article/view/I 24275/I2060 I

15. Lemos CFP, Barros GS, Melo NCV, Amorim FF, Santana ANC. Avaliação do conhecimento em cuidados paliativos em estudantes durante o curso de Medicina. Revista Brasileira de Educação Médica. [Internet].2017[acesso em 05 jul 2019]; 4 I (2):278-82. Disponível em: http://www.scielo. br/pdf/rbem/v4In2/I98I-527I-rbem-4I-2-0278.pdf

16. Mendes EC,Vasconcellos LCF. Cuidados paliativos no câncer e os princípios doutrinários do SUS. Saúde em Debate 39 (106) jul-sep. 2015.

17. Merhy EE, Onocko R. Agir em Saúde: um desafio para o público. São Paulo: Hucitec; 2002.

18. Merhy EE, Magalhães Júnior HM, Rimoli J, Franco TB, Bueno WS. Trabalho em saúde: olhando e experienciando o SUS no cotidiano. São Paulo: Editora Hucitec; 2004

19. Zeferino MT, Carraro TE. Alfred Shutz: Do referencial teórico-filosófico aos princípios metodológicos de pesquisa fenomenológica. Texto e Contexto Enfermagem, Florianópolis, 2013 jul-set; 22(3):826-34.

20. Ferreira Neto J L, Kind L. Produção da saúde e de subjetividades em narrativas de usuários do SUS. Psicologia Política.[Internet].20I7[acesso em I5 jul 2019]; I7(38): I66-80.Disponível em: http://pepsic.bvsalud.org/pdf/rpp/v17n38/v17n38al I.pdf

2I. Castro MC, Cruz P, Grellmann M, Santos W, Fuly P. Palliative care for patients with oncological wounds in a teaching hospital: an experience report. Cogitare Enferm.[Internet].20।4[acesso em I5 jul 2019]; 19(4):84 I-4. Disponível em: https://revistas.ufpr.br/cogitare/article/view/37294

22. Academia Nacional de Cuidados Paliativos (ANCP). Manual de Cuidados Paliativos. São Paulo:ANCP; 2009.

23. Irwin KE, Greer JA, Khatib J, Temel JS, PirIWF.Early palliative care and metastatic non-small cell lung cancer: potential mechanisms of prolonged survival. Chron Respir Dis. [Internet].2013[acesso em 20 jul 2019]; I0(I):35-47. Disponível em: https://www.ncbi.nlm.nih.gov/pubmed/23355404

24. Mota MS, Gomes GC, Coelho MF, Lunardi Filho WD, Sousa LD. Reações e sentimentos de profissionais da enfermagem frente à morte dos pacientes sob seus cuidados. Rev. Gaúcha Enferm. [Internet].20II[acesso em I5 jul 20l9];32(I):I29-35. Disponível em: http://www.scielo.br/ pdf/rgenf/v32nl/al7v32nl.pdf

25. Machado BM,Dahdah DF,Kebbe LM. Caregivers of family members with chronic diseases: coping strategies used in everyday life. Cad. Bras. Ter. Ocup. [Internet].2018[acesso em 25 jul 2019];26(2):299313. Disponível em: http://www.cadernosdeterapiaocupacional.ufscar.br/index.php/cadernos/article/view/I979/996.

Recebido: 2019-11-19

Aceito: 2020-02-II 